\title{
Opportunities of the university in fostering flexible skills of students
}

\author{
$N . V$. Uvarina $^{1 *}$, and $A V$. Savchenkov ${ }^{2}$ \\ ${ }^{1}$ Federal State Budgetary Educational Institution of Higher Education South Ural State Humanitarian \\ Pedagogical University, Chelyabinsk, Russia \\ ${ }^{2}$ Federal State Budgetary Educational Institution of Higher Education South Ural State Humanitarian \\ Pedagogical University, Russia, Chelyabinsk
}

\begin{abstract}
This article is devoted to the problem of education of flexible skills of students in the conditions of the university. Flexible skills are actively included in the educational standards and curricula of educational organizations at various levels, and the problem of their formation is becoming more and more relevant in today's conditions of abundance and general uncertainty. The study was conducted in 2020 in Chelyabinsk. The study involved the youth of the Chelyabinsk region in the number of 371 people aged 17 to 30 years and above, of which 299 (81\%) women and 72 (19\%) men. To assess the formation of groups of flexible skills, an author's questionnaire was developed, and the Schwartz values test (the Schwartz Value Questionnaire) was also used. / The Schwartz method). Based on the results of an empirical study, we came to the conclusion that the flexible skills of the behavioral and need-motivational groups are formed to a greater extent. A significant part of the respondents noted that they have developed communication skills, stability of behavior, as well as the ability to self-development and self-improvement.
\end{abstract}

\section{A problem statement}

Today, representatives of various fields of science, employers, and public figures agree that "flexible skills" are necessary for the effective performance of various professional activities, primarily in the field of" person-to-person" [1]. The theoretical concept of the formation and development of "soft skills" began to be actively developed by Western scientists in the early 90s. Over the past decades, a number of different international and state programs for their development have been proposed abroad. "Soft skills" are included in educational standards, curricula of educational organizations of various levels [2, 3, 4]. Flexible skills are actively included in educational standards, curricula of educational organizations of various levels. In foreign studies, considerable attention is paid to the problem of developing flexible skills. A number of researchers refer to flexible skills as ethics, sociability, independence, self-motivation, energy, and the ability to cooperate $[4,5$, 6]. Hurrell believes that flexible skills are not just individual personal characteristics and

\footnotetext{
*Corresponding author: prof-ped.gpa@mail.ru
} 
aptitudes, they include interpersonal and intrapersonal abilities that facilitate the professional activities of young people in certain aspects.

\subsection{The objective of the work}

The purpose of this study is to identify the level of formation of flexible skills among young people in the region and consider the possibility of their education in the conditions of a pedagogical university. The article presents the results of theoretical research and the results of empirical research.

\section{Results of the research}

Let's turn to the analysis of views on the problem of education of flexible skills in the scientific literature. The main views on this problem can be distributed on several grounds:

- "flexible skills" include such personal qualities as self-motivation, communication and time management skills, the desire for self-education and self-development, empathy, emotional intelligence, and the ability to make decisions in stressful situations $[7,8]$;

- "flexible skills" allow students to solve emerging problems, make informed decisions, think critically and creatively, communicate effectively and build professional relationships, and successfully carry out educational activities [9];

- educational activities may be considered as a leading tool for the formation of "flexible skills" of students [10,11];

- students who have the necessary set of formed "flexible skills" are in professional demand in the conditions of general uncertainty, as it is much easier for them to adapt to the changing conditions of the professional environment $[7,8]$;

- "flexible skills" organically complement the professional competencies acquired during professional training [12, 13].

In this study, we divided the "flexible skills" into four main groups: need-motivational, value-semantic, behavioral, and emotional.

The need-motivational group of flexible skills defines the general orientation and motivation of professional activity and represents a set of needs and motives of an individual's activity, among which one can distinguish personal ones: the need for knowledge, self-development, self-expression, the search for unique authenticity and the need to improve oneself, cognitive motives, achieving success in general, self-realization, self-affirmation. And social - the need for recognition, security, interpersonal needs, the need for social recognition for group recognition, for meaningful relationships, the motives for cooperation [11].

Value-semantic group of flexible skills. It is possible to distinguish a certain cognitive component of value, which reflects, on the one hand, the social function of value in the social world, and on the other - meaning, as "meaning for oneself". And these two components may coincide, or may partially overlap each other. It is the values that have a personal meaning for a person that become the guidelines and regulators of his life and actions, which is manifested in the behavioral component of the value. The value-semantic sphere of the individual performs a number of important functions that affect the formation and development of a person. The flexible skills of the value-semantic group include: goalsetting and the need for self-realization. It should be noted that the value orientations of the individual at the level of normative ideals can not always be realized in behavior due to the limitations of human capabilities, group pressure, compliance with certain traditions, following patterns of behavior and other reasons $[12,15]$.

Behavioral group of flexible skills. It is manifested in the behavior and activity of the subject in the process of his self-presentation. It includes a set of intrapersonal qualities and 
behavioral characteristics of the subject that determine the choice of communicative strategies of his forms of behavior, providing assessment and analysis of his own communicative actions and the actions of other subjects in professional activity, including communicative well-being, confidence in communication, manageability and awareness of actions, actions, self-realization, responsibility, self-regulation and self-control. In the personal aspect, this group includes goal-setting - the presence or absence of goals in life in the future, which give meaning to life, focus and time perspective, assessment of educational and professional prospects: wishes, intentions, dreams related to the educational and professional sphere, family status and activity perspective - goals, intentions related to interests, and the achievement of certain results [17].

A communication strategy is a part of a communication interaction or behavior that uses a variety of verbal and nonverbal means. The strategy is only a general norm of behavior, in some cases it is possible to go beyond the strategy. Communicative tactics differ from the communicative strategy in that tactics are inherent in practical actions in the real process of interaction, and tactics in their scope do not correlate with the communicative strategy, but correlate with a set of communicative tasks, intentions. A tactical move, which is a practical means of achieving a communicative goal, is a communicative intention $[15,16]$.

An emotional group of flexible skills. This group is responsible for emotional inclusion, satisfaction with self-presentation, assessment of the significance of social and role characteristics of interaction through personally determined semantic functions, such as: convergence of values, motivation for self-disclosure, creating the right image in the eyes of others, receiving support and sympathy, etc. Defines ego-well-being: self-consistency of the individual, self-satisfaction, attitude, self-acceptance, self-esteem. Self-esteem is an emotional and evaluative component of the "I-concept". Self-esteem reflects the attitude towards yourself as a whole or to individual aspects of your personality and activities. Selfidentification reflects a person's sense of self-esteem, a sense of self-worth. A positive attitude to everything that comes within the scope of his "I". This makes it possible to interpret, evaluate, and accept a person's own experiences and expectations about themselves and others. The self-identification of a person in the process of communication with other people is especially clearly manifested [14].

Consider the possibilities of universities in the formation of flexible skills of students. For the formation of flexible skills of future teachers, it is necessary to saturate the educational environment of the university with professional and universal value-semantic content. This is possible thanks to the use of educational technologies aimed at organizing productive cooperation between teachers and students. From the point of view of S. A. Shilova [18], for the education of flexible skills, it is necessary to create an emotionally comfortable atmosphere, which implies a free exchange of opinions, active participation of all students in joint work. In addition, according to the author, an effective method of developing "soft skills" is to limit the leading role of the teacher in the organization of educational events, in this case, future teachers have more opportunities for direct communication and interpersonal interaction.

Students ' active extracurricular activities contribute to the acquisition of "soft skills" competencies, so they need to be involved in creative, volunteer, scientific and other types of extracurricular activities, in which they develop leadership and organizational qualities, public speaking skills, the ability to work in a team and take responsibility [20]. The process of developing flexible skills and educational activities mutually enrich each other, and the formed competencies form a solid basis for the professional competence of students.

In the course of the study, we developed a model for educating students ' flexible skills in a university setting (Figure 1). 
The presented model is implemented in the course of educational and extracurricular educational work, as well as in the study of disciplines of the psychological and pedagogical cycle. The greatest interest among students is caused by the gamification technology, which allows introducing the game practices and structures familiar to students in non-game educational contexts [19].

\section{The cognitive block of} flexible skills

1) the ability to think critically and avoid stereotypical thinking (the constant search for new ideas, irrational approaches to solving problems, etc.);

2) the ability to design thinking and predictive (forecasting of development of the situation and behayigus of its subjects, goal setting, creative activity, etc.);

3) the ability to make decisions in situations of lack of time and information constraints (speed of processing the information received, stress, confidence in the loyalty of the decisions taken etc.).

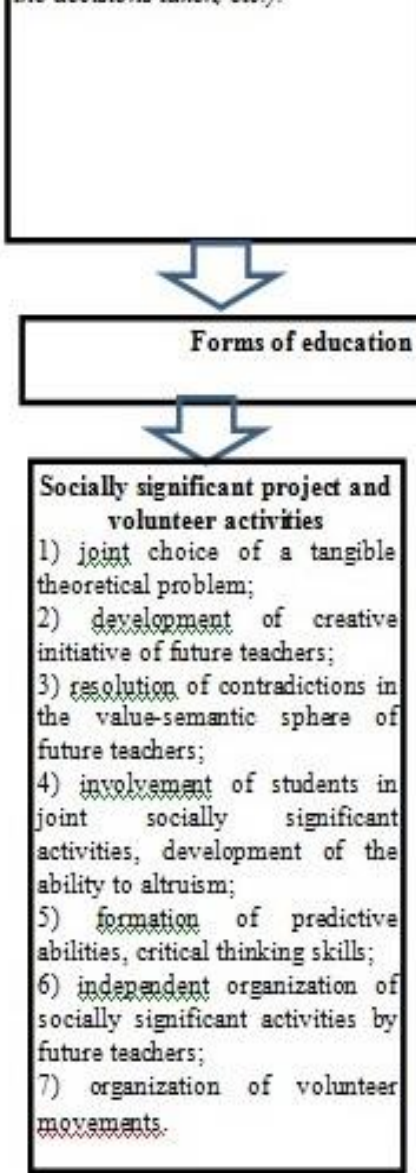

\section{Flexible Skills}

Personality Block

1) emotional intelligence (the ability to recognize, be aware of other people's emotions, understand their intentions, etc.);

2) empathy (conscious empathy with the emotional state of another pers on);

3) the ability to work in a team (the ability to interact effectively, actively participate in socially significant projects, etc.);

4) the ability to motivate the team (the ability to motivate participants in joint activities, the ability to attract their ideas, etc.).
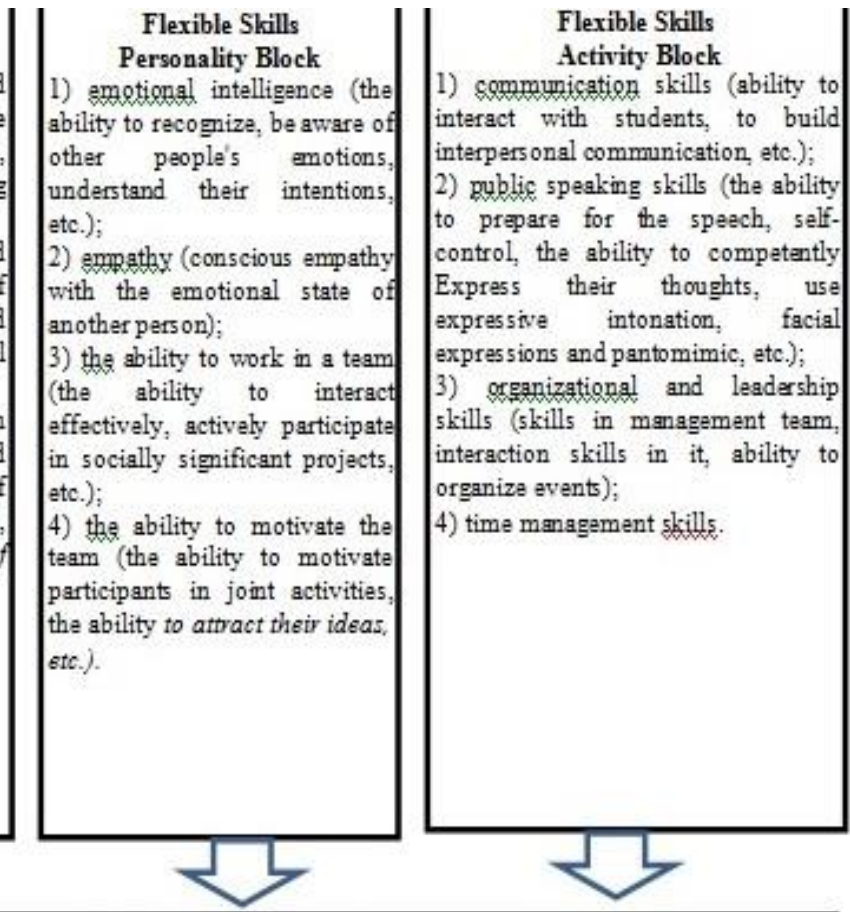

\section{Flexible Skills}

.

(ability to interact with students, to build interpers onal communication etc.);

2) public speaking skills (the ability to prepare for the speech, selfcontrol, the ability to competently Express their thoughts, use expressive intonation, facial expressions and pantomimic, etc.) organizational and leadership skills (skills in management team, interaction skills in it, ability to organize events);

4) time management skills.

institutions



Training sessions

1) exercises aimed at increasing the emotional response, developing the skills of understanding and managing your own emotions;

2) tasks aimed at developing the ability to work in a team, to hear and understand its participants; 3) initiation of useful deeds and socially active activities;

4) exercises aimed at forming future teachers 'motivation to achieve success;

5) the opportunity to communicate with like-minded people and mentors from among the teaching 5 taff during the training.

Fig. 1. Model of education of flexible skills of students in the conditions of the university. 
Within the framework of scientific research on this topic, we conducted an empirical study to identify the level of formation of flexible skills of young people in the region. The study was conducted in 2020 in Chelyabinsk. The study involved the youth of the Chelyabinsk region in the number of 371 people aged 17 to 30 years and above, of which $299(81 \%)$ women and $72(19 \%)$ men. To assess the formation of groups of flexible skills, an author's questionnaire was developed, and the Schwartz values test (the Schwartz Value Questionnaire) was used. / The Schwartz method).

Comparisons of the two groups on quantitative scales were carried out on the basis of the nonparametric Mann-Whitney test. Comparisons of three or more groups on quantitative scales were carried out on the basis of the nonparametric Kruskal-Wallace test. To describe the quantitative indicators, the average value and standard deviation in the format " $\mathrm{M} \pm \mathrm{S}$ "were used. In all graphs for quantitative variables, the arithmetic mean is indicated by a dot, the median is indicated by a horizontal segment, the intra-quartile span is indicated by a rectangle, and the minimum and maximum values are indicated by vertical segments.

To study the influence of several independent variables (factors) on the dependent variable, we used multivariate analysis of variance (ANOVA) - a method that allows us to evaluate not only the influence of each independent variable on a certain indicator (dependent variable), but also to determine the statistical significance of the interaction of these independent variables. The interaction shows whether the magnitude of the impact of a factor depends on the values of other factors (variables).

The statistical significance of different values for binary and nominal indicators was determined using the Pearson Chi-square test.

To describe the central position and absolute spread of the data, the average value and standard deviation in the format " $\mathrm{M} \pm \mathrm{S}$ " were used, and to estimate the relative spread, the coefficient of variation $\mathrm{V}$ was used, which characterizes the uniformity of the indicator and allows you to compare the uniformity of different indicators, regardless of their scale and units of measurement. It is generally assumed that if the coefficient of variation is less than $10 \%$, then the degree of data dispersion is considered insignificant, from $10 \%$ to $20 \%$ average, more than $20 \%$ and less than or equal to $33 \%$ - significant; if the value of the coefficient of variation does not exceed $33 \%$, then the population is considered homogeneous, if more than $33 \%$, then-heterogeneous (Table 1).

Table 1. Shows the overall distribution of the sample of respondents. Descriptive statistics of quantitative indicators.

\begin{tabular}{|c|c|c|c|c|c|}
\hline Flexible skills & N (\%) & $\mathbf{M} \pm \mathbf{S}$ & $\mathbf{V}$ & $\begin{array}{c}\text { Me [LQ; } \\
\text { UQ] }\end{array}$ & $\begin{array}{l}\text { (Min; } \\
\text { Max) }\end{array}$ \\
\hline Behavioral Group & $\begin{array}{c}371 \\
(100.00 \%)\end{array}$ & $\begin{array}{c}11.87 \pm \\
2.33\end{array}$ & $20.00 \%$ & $\begin{array}{c}12.00 \\
{[11.00 ; 14.00]}\end{array}$ & $\begin{array}{l}(4.00 ; \\
16.00)\end{array}$ \\
\hline Value-semantic group & $\begin{array}{c}371 \\
(100.00 \%) \\
\end{array}$ & $\begin{array}{c}5.38 \pm \\
1.63 \\
\end{array}$ & $30.00 \%$ & $\begin{array}{c}5.00 \\
{[4.00 ; 6.00]} \\
\end{array}$ & $\begin{array}{l}(2.00 \\
10.00)\end{array}$ \\
\hline Emotional group & $\begin{array}{c}371 \\
(100.00 \%) \\
\end{array}$ & $\begin{array}{c}7.55 \pm \\
1.78 \\
\end{array}$ & $24.00 \%$ & $\begin{array}{c}8.00 \\
{[6.00 ; 9.00]}\end{array}$ & $\begin{array}{l}(2.00 \\
10.00)\end{array}$ \\
\hline Need-motivation group & $\begin{array}{c}371 \\
(100.00 \%) \\
\end{array}$ & $\begin{array}{c}13.61 \pm \\
2.31 \\
\end{array}$ & $17.00 \%$ & $\begin{array}{c}14.00 \\
{[12.00 ; 15.00]}\end{array}$ & $\begin{array}{l}(7.00 \\
20.00)\end{array}$ \\
\hline
\end{tabular}

Based on Table 1, we can conclude that there are no indicators with incomplete data among the 4 indicators. These volumes are sufficient for statistical analysis of the data and the formation of statistical conclusions. Pearson's criterion of agreement shows that in $90 \%$ of cases the hypothesis of a normal distribution is rejected.

The analysis of the levels of formation of groups of flexible skills of young people in the region in the context of gender differences is presented in Table 2. 
Table 2. Formation of flexible skills of young people in the region (gender differences).

\begin{tabular}{|l|c|c|c|}
\hline \multirow{2}{*}{ Flexible skills } & \multicolumn{2}{|c|}{ gender } & \multirow{2}{*}{ Level P } \\
\cline { 2 - 3 } & Female (N=299) & $\begin{array}{c}\text { Male } \\
(\mathbf{N}=\mathbf{7 2})\end{array}$ & \\
\hline Behavioral Group & $11.85 \pm 2.38$ & $11.94 \pm 2.09$ & 0.9576 \\
\hline Value-semantic group & $5.38 \pm 1.62$ & $5.36 \pm 1.66$ & 0.8197 \\
\hline Emotional group & $7.56 \pm 1.79$ & $7.50 \pm 1.75$ & 0.7868 \\
\hline Need-motivation group & $13.74 \pm 2.27$ & $13.07 \pm 2.43$ & 0.0225 \\
\hline
\end{tabular}

A statistically significant difference was found for the indicator "Need-motivational component" in the "Female" group in relation to the "Male" group (on average by 0.7 ; $\mathrm{P}=$ 0.0225). The most homogeneous distributions between the two groups are observed in the following indicators: "Emotional component", "Value-semantic component" and "Behavioral component" ( $\mathrm{P}>0.7868)$. At the same time, we found that the flexible skills of the behavioral and need-motivational groups are formed to a greater extent, while the female respondents have them formed at a higher level. Table 3 shows the comparative characteristics of the formation of flexible skills of young people by age (Table 3).

Table 3. Age-specific features of the formation of flexible skills of young people in the region.

\begin{tabular}{|c|c|c|c|c|}
\hline \multirow[t]{2}{*}{ Flexible skills } & \multicolumn{3}{|c|}{ Age } & \multirow{2}{*}{$\begin{array}{c}\text { Level } \\
P(\mathrm{df}=2)\end{array}$} \\
\hline & $\begin{array}{l}\text { a) Under } 21 \\
(\mathrm{~N}=84)\end{array}$ & $\begin{array}{l}\text { b) From } 22 \text { to } 30 \\
\text { years old } \\
(N=174)\end{array}$ & $\begin{array}{c}\text { c) Over } 30 \\
\text { years old } \\
(\mathrm{N}=113)\end{array}$ & \\
\hline Behavioral Group & $11.14 \pm 2.45$ & $11.82 \pm 2.30$ & $\begin{array}{c}12.48 \pm \\
2.11\end{array}$ & 0.0003 \\
\hline Value-semantic group & $5.30 \pm 1.53$ & $5.39 \pm 1.72$ & $5.43 \pm 1.57$ & 0.8996 \\
\hline Emotional group & $7.61 \pm 1.89$ & $7.50 \pm 1.87$ & $7.58 \pm 1.55$ & 0.7946 \\
\hline Need-motivation group & $13.24 \pm 2.41$ & $13.62 \pm 2.34$ & $\begin{array}{c}13.86 \pm \\
2.17\end{array}$ & 0.1478 \\
\hline
\end{tabular}

The most significant differences were found for the indicator "Behavioral group" in the group "b) Over 30 years" in relation to the group " a) Under 21 years "(on average by 2.1; P $=0.0083$ ); the indicator" Behavioral component "in the group" b) Over 30 years "in relation to the group" a) Under 21 years " (on average by $1.3 ; \mathrm{P}=0.0003$ ). Thus, the level of formation of groups of flexible skills on average increases with age (on average, by 2 points), and this is mainly due to the behavioral component.

Based on the results of an empirical study, we came to the conclusion that the flexible skills of the behavioral and need-motivational groups are formed to a greater extent. A significant part of the respondents noted that they have developed communication skills, stability of behavior, as well as the ability to self-development and self-improvement. A high level of goal setting indicates the life meaningfulness of the respondents, the orientation and time perspective, the assessment of the educational and professional prospects: wishes, intentions, dreams related to the educational and professional sphere, family status and activity prospects, goals, intentions related to interests, and the achievement of certain results. 
Low results were found for the emotional and value-semantic group of flexible skills. Respondents are more focused on personal values, and professional values are not always accepted by them. Low indicators were identified in terms of self-esteem and selfidentification, and a low level of emotional intelligence and emaptia was revealed. According to the results of the study, it can be concluded about the relevance of the work on the education of flexible skills in the conditions of the university.

We also found that with age, the formation of flexible skills increases in respondents over 30 years of age, the level of formation of all groups of skills at the maximum level.

\section{Conclusions}

According to the results of the study, we came to the following conclusions:

- flexible skills are actively included in educational standards, curricula of educational organizations of various levels. In foreign studies, considerable attention is paid to the problem of developing flexible skills. A number of researchers refer to flexible skills as ethics, sociability, independence, self-motivation, energy, and the ability to cooperate;

- flexible skills, as universal behavioral competencies, are "superprofessional" and act as a personal resource of students, regardless of their individual characteristics and personal characteristics;

- within the framework of our study, flexible skills of young people were divided into four groups: behavioral (stability of behavior, communication skills and strategies, public speaking skills), value-semantic (goal setting, the need for self-realization, integration of personal and professional values), need-motivational (self-development, self-expression and self-motivation) and emotional (emotional intelligence, empathy, emotional stability, self-regulation, stress resistance);

- based on the results of an empirical study, we found that young people have better formed flexible skills of the need-motivational and behavioral group. Young people are more likely to seek self-development, the need for social recognition, and focus on flexible communication strategies. A fairly high level of formation was revealed by such indicators of flexible skills of the behavioral group as self-regulation and self-control. Low indicators were identified for the value-semantic and emotional group of flexible skills;

- the results of an empirical study indicate the importance of work on the education of flexible skills of students in the conditions of the university.

The scientific article was supported by the e-grant of the Russian Foundation for Basic Research № 21-18-00139

\section{References}

1. E.S. Bogdan, Actual problems of the humanities and natural sciences, 2-4, 17-20 (2017)

2. H. Cheng, A. Green, L. Treglown, A. Furnham, B.P. Chapman, Personality and Individual Differences, 117, 205-209 (2017)

3. B. Gendron Revista espanola de educacion comparada, 29, 44-61 (2017)

4. E.A. Gnatyshina, N.V. Uvarina, A.A. Salamatov, A.V. Savchenkov, N.A. Pakhtusova, Revista Espacios, 39, 7 (2018)

5. B.O. Haugland, R.M. Lassen, T. Giske, Nurse Education in Practice, 29, 64-69 (2018)

6. S.A. Hurrell, Human Relations, 69(3), 605-628 (2016)

7. E.V. Karpova, S.I. Kopteva, Yaroslavl Pedagogical Bulletin, 2(107), 114-121 (2019) 
8. E.S. Kilpeleinen, Ideas and Innovations, 2, 23-40 (2019)

9. L.H. Lippman, R. Ryberg, R. Carney, A. Kristin, Child Trends Publication, 56 (2015)

10. L.M. Luchsheva, Problems of modern pedagogical education, 58(3), 323-326 (2018)

11. N.G. Milonova, Professional education in Russia and abroad, 1(25), 107-110 (2017)

12. I.V. Motorina, A.V. Mothorin, Personality in a changing world: health, adaptation, development, 6(2), 305-321 (2018)

13. N.I. Nagimova, M.A. Fakhretdinova, Modern problems of science and education, 6, 88 (2019)

14. E. Purc, M. Front, Psychology, 10, 865 (2019)

15. L.K. Raitskaya, E.V. Tikhonova Bulletin of the Peoples' Friendship University of Russia. Series: Psychology and Pedagogy, 3, 350-363 (2018)

16. I.M. Shilova, Omsk Psychiatric Journal, 1(7), 35-36 (2016)

17. I.K. Tsalikova, S.V. Pakhotina Education and science, 21(8), 187-207 (2019)

18. M.V. Vasilizhenko Modern higher school: innovative aspect, 1(47), 137-148 (2020)

19. T.A. Yarkova, I.I. Cherkasova, Bulletin of the Tyumen State University. Humanitarian sciences. Humanitates, 4, 222-234 (2016)

20. N.V. Uvarina, A.V. Savchenkov, Pakhtusova, E.A. Gnatyshina, O.A. Shumakova, JARDCS Jour of Adv Research in Dynamical \& Control Systems, 12(3), 1206-1213 (2020) 